\title{
Aortic rupture due to pseudocoarctation caused by migrated stent graft
}

\author{
Murat Uğur ${ }^{1}$, İbrahim Alp², İsmail Selçuk², Veysel Temizkan¹, Ali Ertan Ulucan¹, \\ Ahmet Turan Yilmaz
}

\footnotetext{
1) Sultan Abdulhamid Han Training and Research Hospital, Department of Cardiovascular Surgery, MD., Istanbul, Turkey

2) Sultan Abdulhamid Han Training and Research Hospital, Department of Cardiovascular Surgery, Assoc. Dr., Istanbul, Turkey

3) Sultan Abdulhamid Han Training and Research Hospital, Department of Cardiovascular Surgery, Prof. Dr., Istanbul, Turkey
}

\begin{abstract}
Migration of the stent graft is one of the complications of the endovascular aneurysm repair. Sometimes migration might cause fracture of the stent graft. This fracture might be viewed like a coarctation in the computerized tomographic examinations. In this situation, intraluminal aortic pressure of the proximal segment of the aorta will increase and might cause aortic rupture. Herein, we are presenting surgical treatment of the aortic rupture of the aorta, caused by the pseudocarctation of the migrated stent graft 6-year after the endovascular stent graft repair of the abdominal aortic aneurysm.
\end{abstract}

Key words: Aortic aneurysm, coarctation, endovascular procedure, migration, stent fracture. 


\section{Introduction}

Antegrade stent graft migration is one of the complications following endovascular treatment of abdominal aortic aneurysm (AAA). Caudal migration of stent graft might progress due to shortness of the intact aortic neck, small diameter of stent graft or infrarenal native aortic dilatation. Migration precipitates type I and III endoleaks, which poses high risk factor for aotic rupture related with increased morbidity and mortality. Fracture of stent graft develops where the endurance of the implant is less. Collapsing of the stent graft leads to an aortic pseudocoarctation, that increases blood pressure on the proximal aortic tissue. This increased blood pressure might cause dilatation in proximal aorta and other related complications, especially life-threatening acute rupture of the aorta. In this article, we are reporting surgical treatment of the acute aortic rupture which is caused by the pseudocoarctation of the stent graft.

\section{Case report}

A 72 year old male patient was admitted to the emergency service with the complaints of a suddenly developed abdominal distention and pain. Six years ago, endovascular aneurysm repair (EVAR) was performed to the patient with the diagnosis of the abdominal aortic aneurysm at another institution. He was checked up routinely. There was not aortic dilatation, and stent graft was normal position during the examinations. He was admitted to the emergency service with hypertensive crisis a week before. At that time, he was

Figure 1. View of pseudocoarctation in transvers axis of CT angiogram

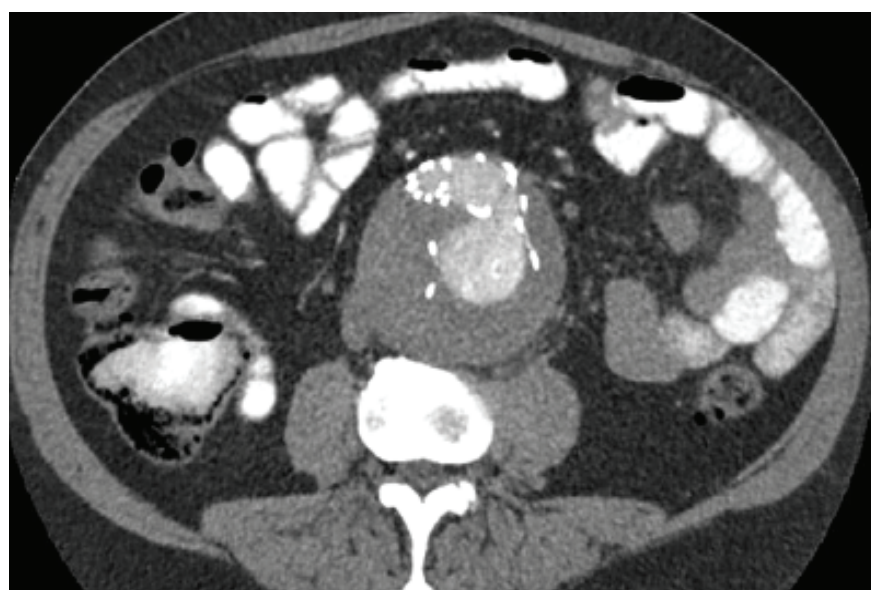

discharged from the hospital after his arterial pressure was controlled with medications. He did not have any symptoms for a week. However sudden abdominal pain was developed one week after the hypertensive crisis.

He was fatigue, his face was pale and his blood pressure and rate were normal. Abdominal distention and pulsatile mass was revealed in the physical examination. There was retroperitoneal fluid in urgent ultrasonography and a migration of the stent graft and aortic rupture was diagnosed with computerized tomography (CT) (Figure 1-2).

The patients underwent urgent operation with these findings. After laporatomy, aorta was explored at the juxtarenal level. Aortic clamp was applied proximal of the renal arteries. After clamping of the iliac arteries, retroperiteon was opened and aortotomy was performed. The stent graft which was migrated to the caudally was excluded. Aorto-biiliac bypass operation with 20/10 Dacron graft was performed. Postoperative period was uneventful and the patient was discharged from the hos-

Figure 2. 3D view of pseudocoarctation of the stent graft in CT angiography.

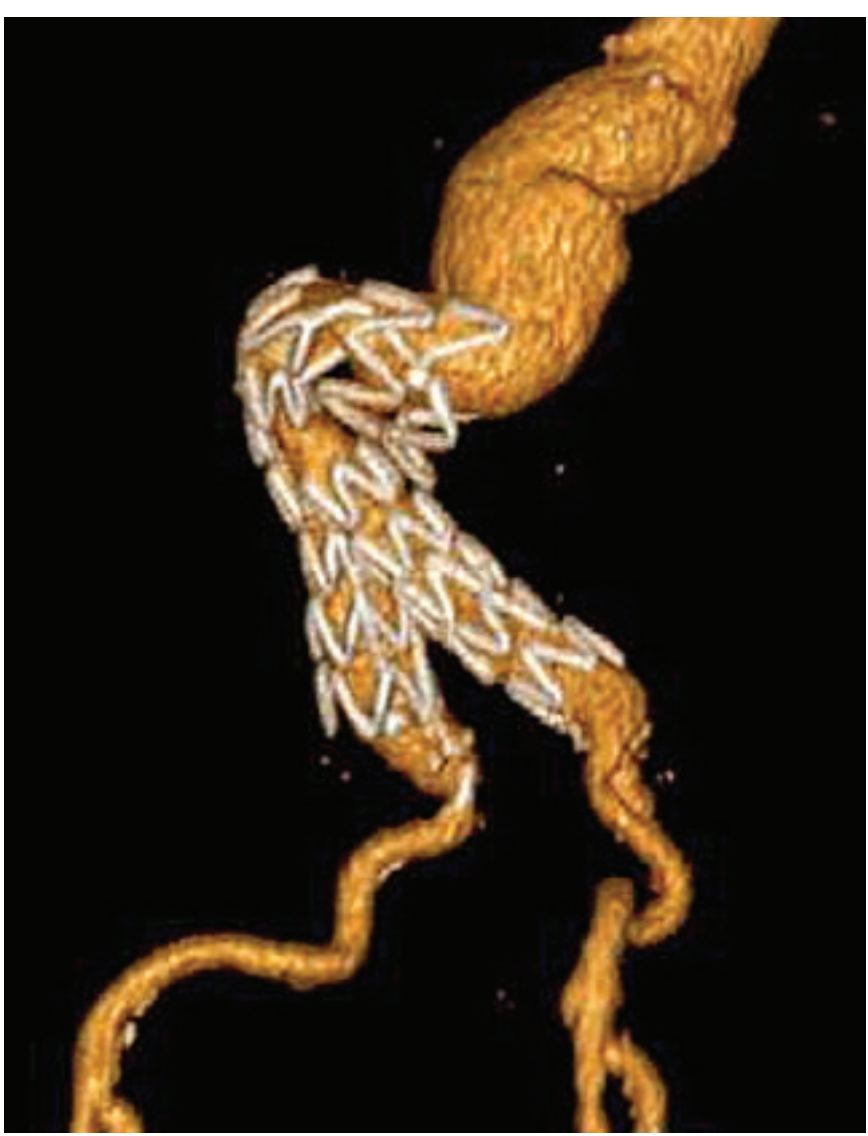


pital at postperative 10th day.

\section{Discussion}

After EVAR procedure, the complications of endoleak, migration, graft thrombosis, infection, aortoenteric fistula, new aneurysm, fabrik erosian, detachment of the components, fracture of the stent, and rupture have been reported. ${ }^{1-4}$ Aortic rupture might develop due to fracture or migration of the stent graft. In our case migrated stent graft was fractured and was mimicking a coarctation. We are presenting this situation as pseudocoarctation; a new complication of the EVAR procedure. Pseudocoarctation of the stent graft increases risks of aortic dilatation and rupture due to increased intraaortic pressure in the proximal aorta.

It is an important complication of the EVAR which necessitates urgent operation. In our case, aortic rupture, caused by increased intraaortic pressure, occured at proximal part of the aneurysmal sac. Dehissence of proximal segment of the stent graft might be developed due to hypertensive crisis and stent graft was migrated one week after the crisis. This migration caused fracture of the stent graft and coarctation-like view was observed in the CT examination. This acute narrowing of the aortic lumen increased proximal intra-aortic pressure and caused acute aortic rupture.

The purpose of the endovascular treatment of the AAA is to protect the aneurysm sac from the aortic rupture and to decrease the risks of the aortic rupture which is related with increased mortality. Aneurysm's neck is unstable, aortic dilatation continues unless it is fixed safely. ${ }^{4}$ Stent graft migration occurs in the cases of dilatation of the proximal neck and in the absence of the fixation systems of the stent grafts. ${ }^{5}$ Migration is directly associated with dilatation of the aneurysmatic aorta and aortic rupture. Litwinski et al. ${ }^{6}$ reported that short proximal fixation and inferior positioned stent graft are the risk factors for the migration in the long term; however length and diameter of the aorta, aneurysm diameter, usage of proximal cuff and oversizing are not risk factors for the migration. The distance between the renal artery and stent graft increases the risk of migration $5.8 \%$ per $\mathrm{mm}$, while proximal fixation length decreases $2,5 \%$ per $\mathrm{mm}^{7}$
Graft migration facilitates type 1 endoleak, thus improves dilatation of the aneurysmatic sac and rupture. ${ }^{3}$ Migration risk increases by the time and it develops in an average of 30 months following the procedure. Zarins et al. ${ }^{7}$ reported freedom from the migration rates $98.6 \%, 93.4 \%$ and $81.2 \%$ at 1 st, 2 nd and 3rd years, respectively. In our case, EVAR was performed 6 years before the migration and stent graft was at normal position in all control examinations. Aortic rupture occurred due to migrated stent graft which is developed one week after the hypertensive crisis. In the follow up of the EVAR procedure, regulation of the arterial pressure with medications, and detailed examination with the suspicion of aortic rupture in the hypertensive crisis is important to decrease the risks of mortality and morbidity.

Dilatation and lengthening of the infrarenal aorta even after the surgical repair of AAA was reported. This situation might malposition the proximal suture line to the caudally and might lead to pseudoanerysm. ${ }^{6}$ Increasing in the infrarenal diameter of aortic neck, shortening of the infrarenal neck are the damaging factors of the integrity of the stent graft. Endoleak, migration and rupture develops due to damage of the proximal fixation. Caudal migration with keeping proximal landing-zone (that stent graft did not fall into aortic sac) is a benign clinical situation. ${ }^{6}$ Fixation system at the proximal segment of the stent graft and postprocedural balloon dilatation might be used to decrease the risk of graft migration. In addition, effective radial force with efficient oversizing prevents migration by sealing the stent graft to the aortic wall. ${ }^{6}$ It was also reported that extension of the stent graft through to the iliac bifurcation might be effective to prevent graft migration. ${ }^{8}$ Complications of EVAR have been decreasing with development in the stent graft technology which improves stent graft fixation to the aortic wall.

\section{Conclusion}

Pseudocaorctation due to fracture of the stent graft might cause aortic dilatation and rupture of the proximal aorta. Acute hypertensive crisis, even after many years of EVAR procedure, might migrate stent graft caudally and be cause of the pseudocoarctation and aortic rupture. 


\section{References}

1. Brinster CJ, Fairman RM, Woo EY, Wang GJ, Carpenter JP, Jackson BM. Late open conversion and explantation of abdominal aortic stent grafts. J Vasc Surg 2011;54:42-6

2. Klonaris C, Lioudaki S, Katsargyris A, Psathas E, Kouvelos G, Doulaptsis $\mathrm{M}$, et al. Late open conversion after failed endovascular aortic aneurysm repair. J Vasc Surg 2014;59:291-7.

3. Rutherford RB. Open versus endovascular stent graft repair for abdominal aortic aneurysms: an historical view. Semin Vasc Surg 2012;25:39-48.

4. Chuter TA. Durability of endovascular infrarenal aneurysm repair: when does late failure occur and why? Semin Vasc Surg 2009;22:102-10.

5. Pintoux D, Chaillou P, Azema L, Bizouarn P, Costargent A, Patra P, et al. Long-term influence of suprarenal or infrarenal fixation on proximal neck dilatation and stentgraft migration after EVAR. Ann Vasc Surg 2011;25:1012-9

6. Litwinski RA, Donayre CE, Chow SL, Song TK, Kopchok G, Walot I, et al. The role of aortic neck dilation and elongation in the etiology of stent graft migration after endovascular abdominal aortic aneurysm repair with a passive fixation device. J Vasc Surg 2006;44:1176-81.

7. Zarins CK, Bloch DA, Crabtree T, Matsumoto AH, White RA, Fogarty TJ. Stent graft migration after endovascular aneurysm repair: importance of proximal fixation. J Vasc Surg 2003;38:1264-72

8. Benharash P, Lee JT, Abilez OJ, Crabtree T, Bloch DA, Zarins CK. Iliac fixation inhibits migration of both suprarenal and infrarenal aortic endografts. J Vasc Surg 2007;45:250-7.

Received: 06/11/2017

Accepted: $12 / 02 / 2018$

Published: 15/03/2018

Disclosure and conflicts of interest:

The authors declare no conflict of interest.

\section{Corresponding author:}

Murat Uğur

Mail: drmugur@gmail.com 